\title{
An Update on Adverse Cutaneous Drug Reactions in HIV/AIDS
}

\author{
Koraisha Hoosen ${ }^{a} \quad$ Anisa Mosam ${ }^{a} \quad$ Ncoza Cordelia Dlova ${ }^{a}$ \\ Wayne Grayson ${ }^{\mathrm{b}, \mathrm{c}}$ \\ a Department of Dermatology, Nelson R Mandela School of Medicine, University of \\ KwaZulu-Natal, Durban, South Africa; ${ }^{b}$ Division of Anatomical Pathology, School of \\ Pathology, Faculty of Health Sciences, University of the Witwatersrand, Johannesburg, \\ South Africa; ' $A m p a t h$ National Laboratories, Johannesburg, South Africa
}

\author{
Keywords \\ Drug reaction $\cdot$ Cutaneous reaction · HIV
}

\begin{abstract}
Background: The global mortality from HIV and the cutaneous burden of infective, inflammatory and malignant diseases in the setting of AIDS have significantly declined following the advent of highly active antiretroviral therapy. Regrettably, there has been a contemporaneous escalation in the incidence of adverse cutaneous drug reactions (ACDR), with studies attesting that HIV-positive individuals are a hundred times more susceptible to drug reactions than the general population, and advanced immunodeficiency portending an even greater risk. Several variables are accountable for this amplified risk in HIV. Summary: Adverse reactions to trimethoprim-sulfamethoxazole are the most common, increasing from approximately 2-8\% in the general population over to $43 \%$ amongst HIV-positive individuals to approximately $69 \%$ in subjects with AIDS. Antituberculosis drugs and antiretrovirals are also well-known instigators of ACDR. Cutaneous reactions range from mild morbilliform eruptions to severe, lifethreatening manifestations in the form of Stevens-Johnson syndrome/toxic epidermal necrolysis. Histological features vary from vacuolar interface changes to full-thickness epidermal necrosis with subepidermal blister formation. A precipitous diagnosis of the ACDR, clinically and histologically if necessary, together with the isolation of the causative drug is critical. The identification process, however, is often complex and multifaceted due to polypharmacy and inconclusive data on which drugs are the most likely offending agents, especially against the background of tuberculosis co-infection. Key Messages: Whilst milder cutaneous reactions are treated symptomatically, severe reactions mandate immediate treatment discontinuation without rechallenge. Further studies are required to establish safe rechallenge guidelines in resource-limited settings with a high HIV and tuberculosis prevalence.
\end{abstract}


Hoosen et al.: Cutaneous Drug Reactions in HIV

\section{Introduction}

Drug reactions are a significant cause of morbidity and mortality worldwide. Studies have established that HIV-positive individuals are a hundred times more susceptible to drug reactions than the general population, and advanced immunodeficiency portends an even greater risk [1]. Multiple heterogeneous factors are responsible for the substantial risk in HIV, including polypharmacy, slow acetylator status, relative glutathione deficiency, CD4+ T-cell counts of $<200$ cells $/ \mathrm{mm}^{3}$ or $>25$ cells $/ \mathrm{mm}^{3}$ [2], latent cytomegalovirus and Epstein-Barr virus infections [3] and high CD8+ T-cell counts $>460$ cells $/ \mathrm{mm}^{3}$.

The majority of adverse drug reactions are due to trimethoprim-sulfamethoxazole (TMP/ SMX), other sulphonamide drugs and penicillins, accounting for $75 \%$ of all reported cases, of which adverse reactions to TMP/SMX are the most common, increasing from approximately $2-8 \%$ in the general population over $43 \%$ amongst HIV-positive individuals to approximately $69 \%$ in subjects with AIDS [4-6]. One of the postulated reasons for the discernible incidence of reactions to TMP/SMX is the systemic glutathione deficiency in these individuals, which increases the probability of circulating toxic intermediates like hydroxylamine derivatives which play a key role in inciting drug reactions [7]. Other drugs that are renowned for engendering adverse reactions include antituberculosis (anti-TB) drugs, antiretrovirals, nonsteroidal anti-inflammatory drugs and anticonvulsants.

In this review, adverse cutaneous drug reactions (ACDR) due to the most commonly prescribed medications (including TMP/SMX, anti-TB drugs and antiretrovirals) in the setting of HIV will be discussed. Prompt diagnosis of the ACDR - together with the identification and immediate removal of the offending drug where applicable, as well as treatment of the reaction - is crucial for preventing further progression of the adverse reaction whilst simultaneously ensuring appropriate alternative treatment, where necessary, for the underlying disorder, bearing in mind that HIV-positive patients are often co-infected with opportunistic infections [8].

\section{Details and Discussion}

\section{Diagnosis of ACDR}

A thorough knowledge of the presentation of ACDR is essential for establishing a diagnosis. A meticulous history to ascertain the onset of skin lesions and a temporal relationship to the drug, followed by a detailed clinical examination to determine the morphological type of the mucocutaneous reaction, must be taken. For more severe reactions, investigations should include a full blood count with a differential white cell count, urea and electrolytes and a liver function test. A skin biopsy for histopathological confirmation can be undertaken in ambiguous cases. Table 1 summarises the major ACDR associated with HIV infection, with an emphasis on their salient clinical and dermatopathological features.

The most common presentation of ACDR is that of a morbilliform eruption (Fig. 1a) 7-14 days after initiation of therapy which resolves on withdrawal of the offending drug. The rash is a pruritic, symmetrical, erythematous, maculopapular eruption usually involving the trunk, intertriginous areas and sparing the face. Other clues are fever, headache, myalgia, arthralgia, granulocytopenia, thrombocytopenia and raised liver enzyme levels. Morbilliform eruption accounts for $95 \%$ of cutaneous adverse drug reactions $[9,10]$. A skin biopsy will reveal a variable, perivascular, dermal lymphocytic infiltrate, sometimes with subtle vasculopathic features. There is mild accompanying lymphocytic exocytosis and spongiosis (Fig. 1b), while careful examination will reveal scattered apoptotic keratinocytes. Scattered eosinophilic leucocytes are usually present amid the dermal infiltrate, and this may serve as a point of 
Hoosen et al.: Cutaneous Drug Reactions in HIV

Table 1. Spectrum of adverse cutaneous drug reactions in HIV-infected patients, with a synopsis of their respective clinical and histopathological features

\begin{tabular}{ll}
\hline Drug reaction & Clinical presentation \\
\hline Morbilliform & $\begin{array}{l}\text { Erythematous, maculopapular, measles- } \\
\text { like exanthem (Fig. 1a) [9] }\end{array}$
\end{tabular}

Histopathology

Erythema multiforme

Urticaria eruption

Lichenoid drug eruption

Vasculitis

Stevens-Johnson syndrome

Toxic epidermal necrolysis
Erythematous, iris-shaped papules and vesicobullous lesions on extremities and mucosal surfaces (Fig. 2a, b) [9]

Transient erythematous pruritic wheals Angioedema: deeper, more painful and less pruritic swellings/plaques affecting the skin and mucosal surfaces, in particular the lips and tongue [9]

Dusky, often annular macules or plaques, sometimes with blistering, which heal with hyperpigmentation [9] (Fig. 3a)

Pruritic, violaceous eruption similar to lichen planus, healing with dusky grey pigmentation [9]

Palpable purpura accentuated on extremities; more extensive eruptions present with plaques, ulcers and blisters [9]

Erythema multiforme lesions involving $\geq 2$ mucosal surfaces; may occur with skin detachment $<10 \%$ of the total body surface area (Fig. 6a-c) [9]

A syndrome which begins with erythema and tenderness of the skin, widespread erythema multiforme and necrotic lesions, progressing to stripping of the skin of $>30 \%$ of the body surface area (Fig. 7a, b) [9]
Usually a variable, superficial, perivascular infiltrate of lymphocytes and eosinophils is present; there may be associated vacuolar interface changes, scattered apoptotic epidermal cells and spongiosis (Fig. 1b) $[3,10,11]$

Vacuolar interface dermatitis with spongiosis and exocytosis; in druginduced cases there is significant keratinocyte apoptosis (Fig. 2c), sometimes involving acrosyringial keratinocytes, as well as microscopic blister formation and more intense pigmentary incontinence; papillary dermal oedema is present in papular lesions; IMF testing may confirm deposits of IgM and complement C3 in the walls of superficial dermal blood vessels $[10,11]$

Acute urticaria-interstitial dermal oedema, dilated venules with endothelial swelling and minimal inflammatory cells; chronic lesions present with interstitial dermal oedema, perivascular and interstitial mixed cell infiltrate with variable numbers of lymphocytes, eosinophils and neutrophils; in angio-oedema, the infiltrate and oedema extend into the subcutis [10]

Scattered necrotic keratinocytes are often seen in the epidermis; frequent hydropic degeneration of the basal layer leads to pigmentary incontinence; confluent keratinocyte apoptosis may occur, while detachment of the epidermis can lead to blister formation (Fig. 3b) $[10,11]$

The histological findings may be similar to lichen planus (Fig. 4a), but distinguishing features of drug-induced lichenoid eruption include numerous eosinophils, parakeratosis and perivascular inflammation around mid and deep dermal plexuses (Fig. 4b) $[10,11]$ Neutrophilic/leucocytoclastic vasculitis of postcapillary venules, characterised by vascular damage with endothelial swelling and fibrin deposition (fibrinoid degeneration), extravasation of red blood cells and neutrophilic infiltration with fragmentation of their nuclei (leucocytoclasis) involving the superficial dermis; more extensive lesions present with pan-dermal involvement with necrosis and ulceration; prominent oedema leads to subepidermal blister formation, and dense neutrophilic inflammation leads to pustule formation (Fig. 5) [10-12]

Similar to erythema multiforme/toxic epidermal necrolysis

Characterised by numerous necrotic keratinocytes, often with fullthickness epidermal necrosis and a subepidermal blister (Fig. 7c), which may contain extravasated erythrocytes; papillary dermal melanophages are present in late lesions; IMF studies may show diffuse epidermal deposition of immunoglobulin and complement [10]

IMF, immunofluorescence.

distinction from the acute HIV exanthem, which has very similar histological features [3, 10-12].

The following signs are clues to a life-threatening reaction:

- Confluent erythema, palpable purpura, blisters, skin necrosis and mucosal erosions

- Urticaria, tongue swelling, dyspnoea, wheezing and hypotension

- Fever $>40^{\circ} \mathrm{C}$, enlarged lymph nodes, arthralgia/arthritis, eosinophilia $>1,000 / \mu \mathrm{L}$, lymphocytosis with atypical cells, and raised liver enzymes 

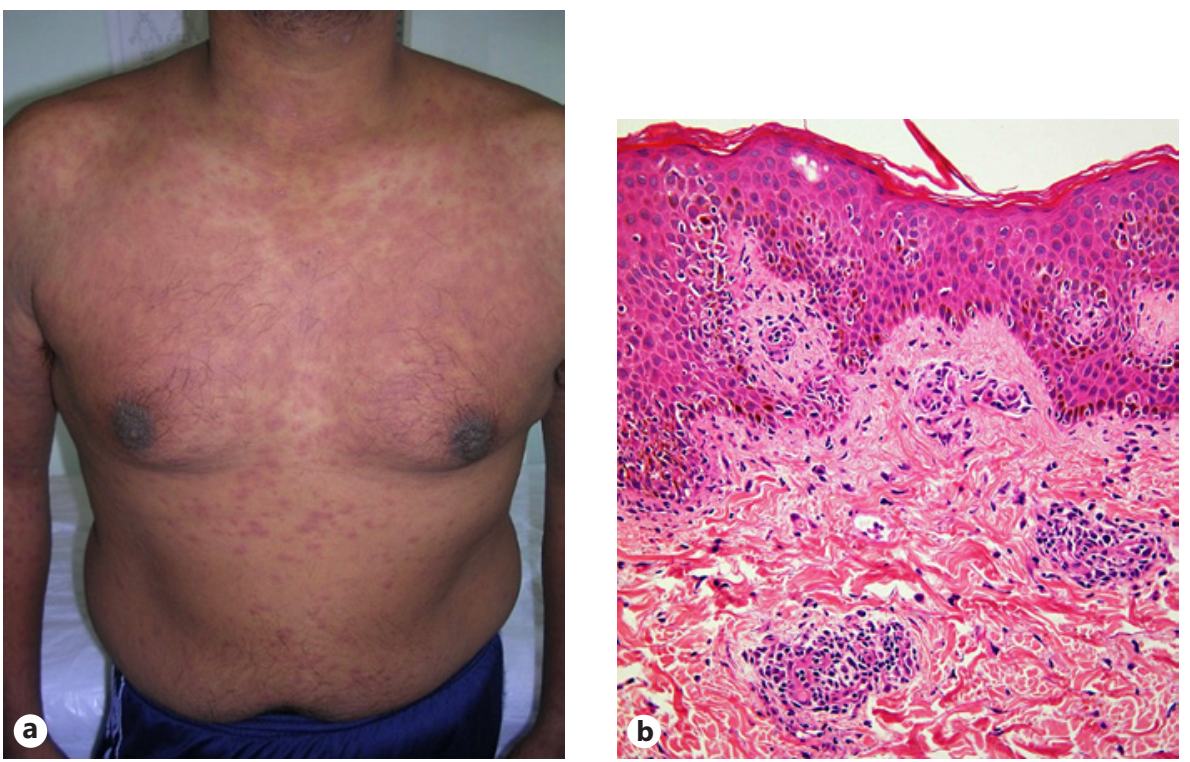

Fig. 1. Morbilliform rash. a Erythematous maculopapular exanthem. b Skin biopsy showing perivascular lymphocytic infiltrate accompanied by mild exocytosis and spongiosis, with rare apoptotic basal keratinocytes.

\section{ACDR to TMP/SMX}

TMP/SMX (cotrimoxazole) is the most common cause of ACDR in HIV. The incidence in the general population is $2.6-8 \%$, increasing to $43-69 \%$ in patients with HIV/AIDS [4-6]. A recent study conducted in Taiwan aimed to determine the risk factors for TMP/SMXrelated ACDR in patients with Pneumocystis jirovecii pneumonia (PJP) and AIDS. The study determined that ACDR were common and occurred in $47.6 \%$ of the patients, mostly within the first 2 weeks of therapy, and that daily doses of $>16 \mathrm{mg} / \mathrm{kg}$ of TMP/SMX and an age $>34$ years were significant risk factors [13]. Mutations in candidate genes have been found to be associated with SMX hypersensitivity. Glutamate-cysteine ligase catalyses a crucial step in glutathione biosynthesis. A single nucleotide polymorphism in the glutamatecysteine ligase catalytic subunit (GCLC) has been associated with reduced GCLC mRNA expression and SMX-induced hypersensitivity in HIV/AIDS, playing a role in idiosyncratic drug reactions [14].

Although severe reactions do occur, overall approximately $50-60 \%$ of patients on TMP/ SMX will experience a morbilliform reaction with associated fever 1-2 weeks after the initiation of therapy. In this setting, the drug can be continued with symptomatic therapy including systemic antihistamines and topical corticosteroids [15]. Weekly assessment and patient education about danger signs are important. If the rash persists, the dose should be reduced. If this is still ineffective, oral corticosteroids at $0.5 \mathrm{mg} / \mathrm{kg}$ should be prescribed up to a maximum of 21 days. Rechallenge is safe for patients with non-life-threatening hypersensitivity [16]. Desensitisation of patients with documented, non-life-threatening ACDR has been shown to effectively induce tolerance in $63 \%$ of cases [17]. However, these patients requiring rechallenge and desensitisation should be referred to a tertiary centre.

Erythema multiforme (Fig. 2a, b) may be a precursor to a more severe reaction (StevensJohnson syndrome [SJS] or toxic epidermal necrolysis [TEN]). Skin biopsy will reveal lymphocytic vacuolar interface dermatitis, with multiple dyskeratotic and apoptotic keratinocytes present at various levels within the epidermis (Fig. 2c) [9-11]. TMP/SMX can also be asso- 

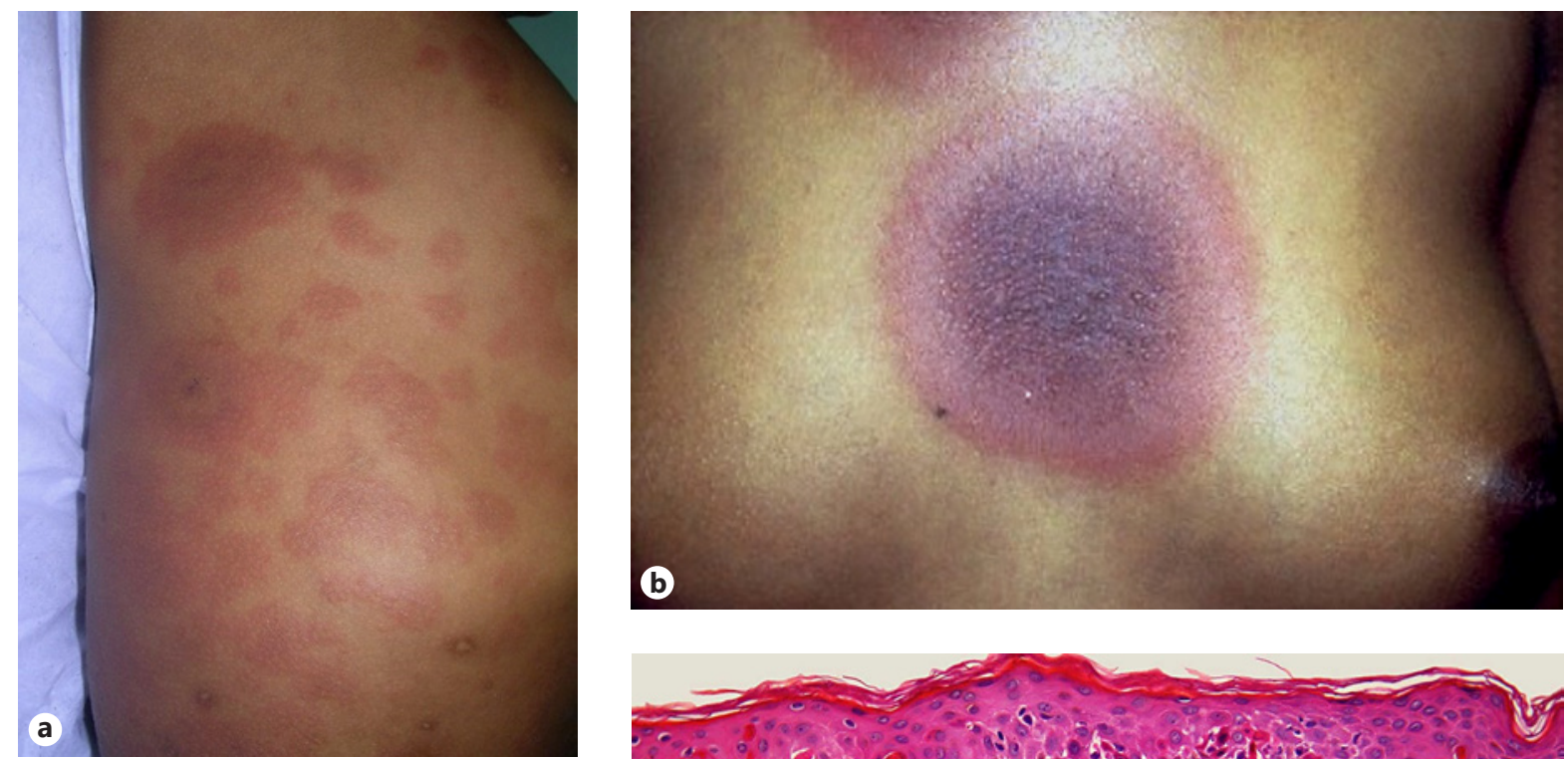

Fig. 2. Erythema multiforme. a Urticarial plaques with targetoid centres. b Classic targetoid lesion. c Microscopic picture predominated by lymphocytic vacuolar interface dermatitis with widespread apoptosis and dyskeratosis of epidermal keratinocytes.

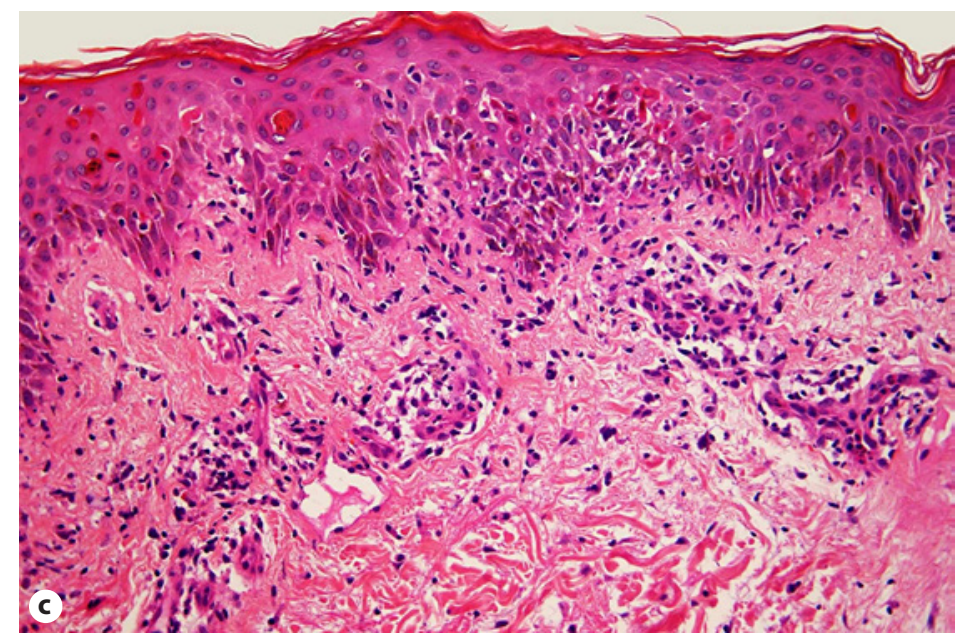

ciated with a fixed drug eruption, which may be bullous (Fig. 3a) or even generalised. Although erythema multiforme and fixed drug eruption share many histological features, the latter tends to exhibit more pronounced pigmentary incontinence. Subepidermal bulla formation may ensue as a consequence of confluent keratinocyte apoptosis and pronounced basal vacuolar degeneration (Fig. 3b) [9-11].

\section{ACDR to Anti-TB Therapy}

Severe cutaneous hypersensitivity historically has been an extremely rare complication of anti-TB therapy in African patients. However, there has been an increase in both morbilliform and severe adverse cutaneous reactions to anti-TB drugs in HIV-infected patients (23\% in one series [18]). The initiation of highly active antiretroviral therapy for HIV and TMP/SMX for PJP prophylaxis simultaneously with anti-TB therapy often confounds the situation, making it extremely difficult to isolate the offending agent, as both TMP/SMX and nevirapine (NVP) are well-documented causes of severe ACDR [19-21].

Data on the incidence of ACDR to anti-TB therapy are limited. In a primary care clinic in South Africa, serious adverse reactions to anti-TB drugs occurred in $13 \%$ of non-HIV-infected patients compared to $27 \%$ of HIV-infected patients [22]. There is currently no consensus regarding which drugs are most frequently implicated in ACDR [19]. Some authors suggest pyrazinamide, whereas others propose streptomycin as the most frequent offender $[23,24]$. 

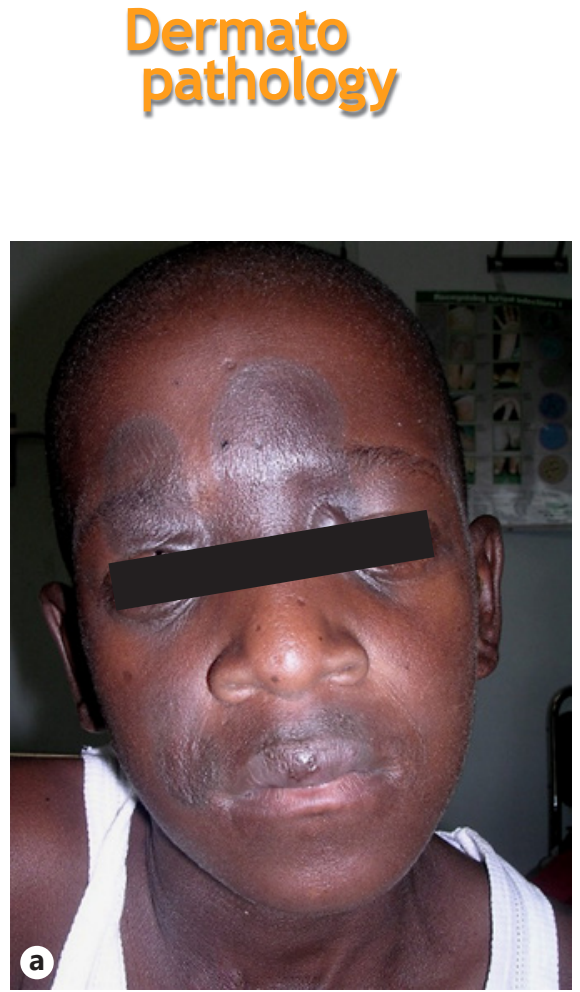

Dermatopathology 2019;6:111-125 DOI: $10.1159 / 000496389$

(c) 2019 The Author(s). Published by S. Karger AG, Basel www.karger.com/dpa

Hoosen et al.: Cutaneous Drug Reactions in HIV

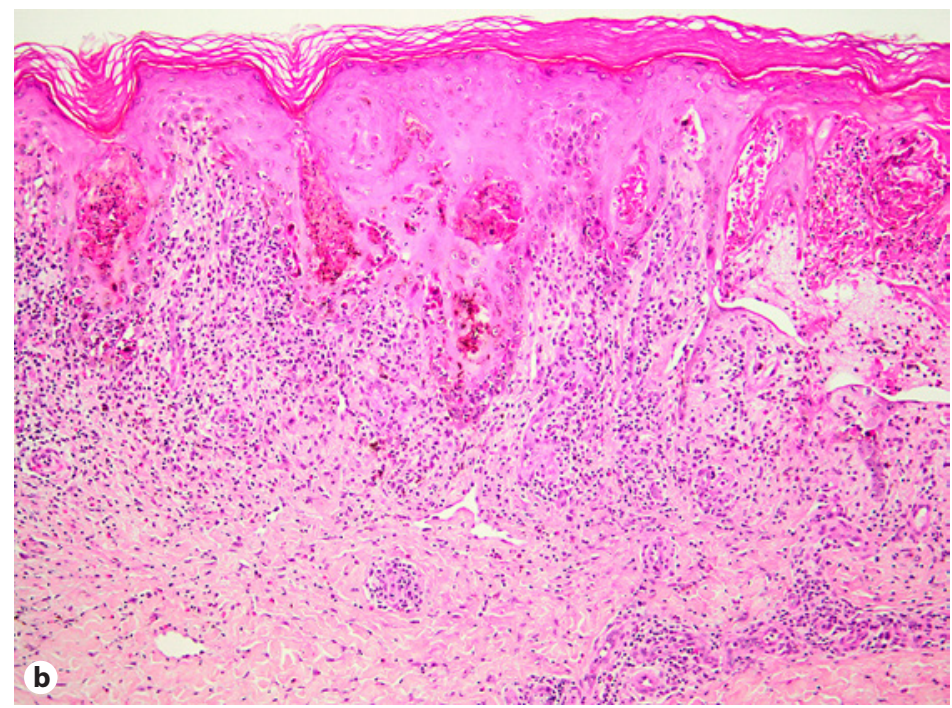

Fig. 3. Fixed drug eruption. a Dusky, annular macules with associated blistering. b Confluent keratinocyte dyskeratosis and apoptosis is seen, with evolving subepidermal bulla formation to the right of the field.

Others have identified rifampicin as the most common cause in HIV-infected patients compared to non-HIV-infected patients [19].

A 2-year retrospective study assessed 820 cases of TB treated in the Respiratory Unit in Penang Hospital, Penang, Malaysia. The aforementioned study revealed that ACDR were frequent particularly in HIV-infected patients, and that pyrazinamide was the most consistent offending drug, followed by streptomycin, ethambutol, rifampicin and isoniazid in order of decreasing frequency. Most reactions occurred within the first 2 months after the initiation of anti-TB treatment, and morbilliform rashes were most common, accounting for $73.3 \%$ of the cases [25]. In a setting of high TB and HIV burden, a recent study in Cape Town, South Africa, determined that rifampicin was the most common cause of reintroduction reactions $[19,26]$.

The mortality due to ACDR depends on the type of the reaction, from mild and selflimiting in the morbilliform type to severe and life-threatening in SJS/TEN.

\section{Morphological Types of ACDR to Anti-TB Drugs}

- Morbilliform reactions are most common, accounting for $95 \%$ of all cases, and presenting within the first 7-14 days after initial drug exposure; these are usually self-limiting without the need for treatment interruption [27]; morbilliform reactions can, however, present as precursors to more severe reactions such as SJS/TEN [28]

- Drug hypersensitivity syndrome (DHS) - also known as drug rash with eosinophilia and systemic symptoms - is a severe reaction associated with a high mortality and a latency period of 3 weeks or longer [29]; anti-TB drugs reported to cause DHS include isoniazid, rifampicin, streptomycin and pyrazinamide $[19,25,30]$

- SJS/TEN is associated with significant mortality and has been observed with rifampicin, pyrazinamide, isoniazid, ethambutol, streptomycin, cycloserine and fluoroquinolones $[19,28,31-35]$

- Lichenoid drug eruptions initially present as pruritic erythematous macules progressing to violaceous, polygonal papules often involving the oral and genital mucosa; their onset 
Fig. 4. Lichenoid drug eruption. a The histological picture in this example is strikingly reminiscent of lichen planus. b However, a mid and deep dermal perivascular lymphocytic infiltrate containing modest numbers of eosinophils and plasma cells offers a useful diagnostic clue.
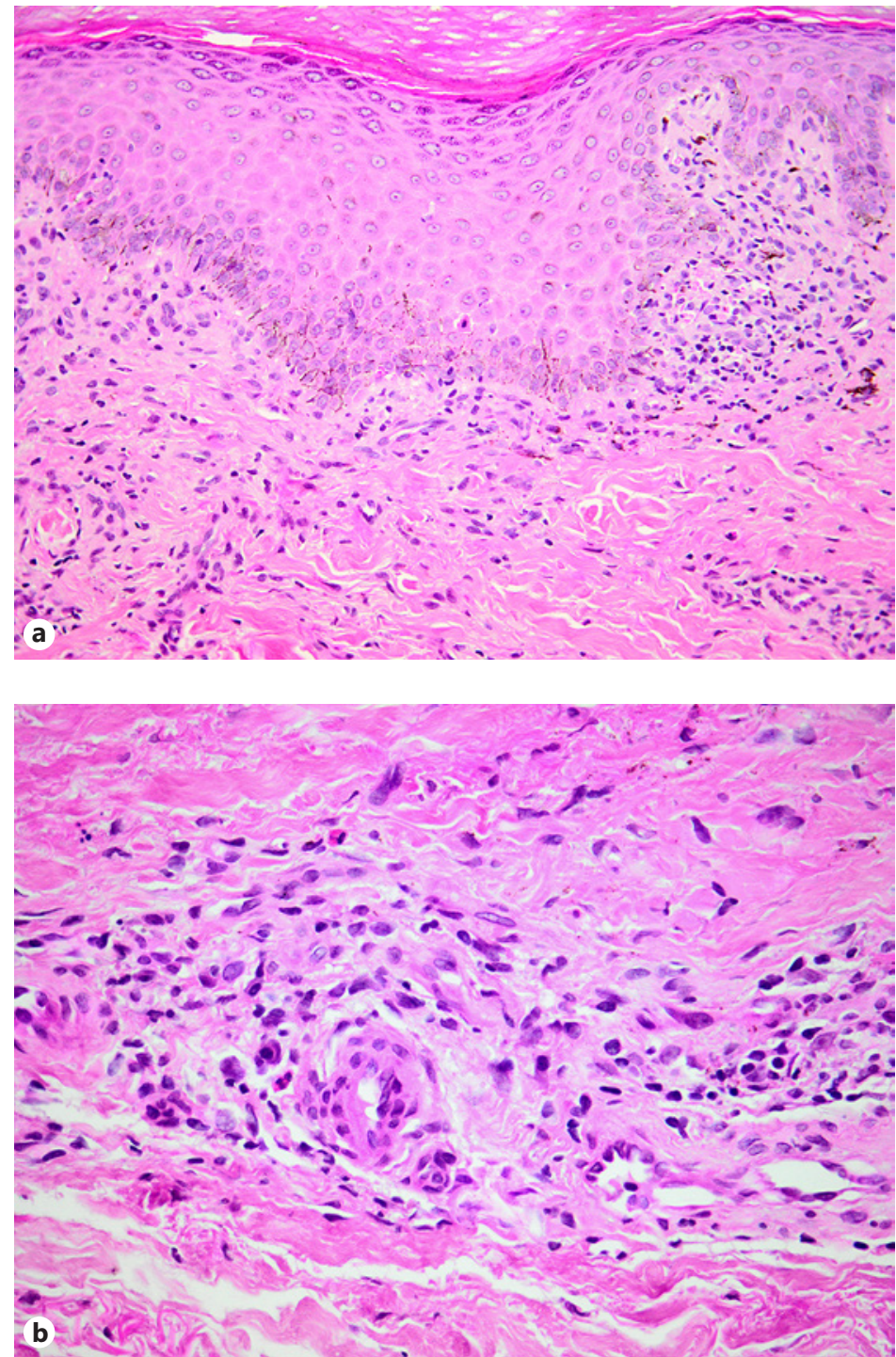

is usually within a few months but can present as early as after a few days, often with spontaneous resolution on drug withdrawal, sometimes with persistent postinflammatory hyperpigmentation [19]; lichenoid drug eruptions can occur secondary to isoniazid, pyrazinamide and ethambutol [25, 36, 37]; although the histopathological picture is often remarkably reminiscent of lichen planus (Fig. 4a), the presence of a deeper dermal inflammatory infiltrate harbouring an admixed contingent of eosinophilic leucocytes and plasma cells (Fig. 4b) may alert one to a pharmacological aetiology $[10,11]$

- Cutaneous vasculitis due to anti-TB therapy is rare but has been reported with rifampicin and pyrazinamide [38-40]; skin biopsy in such cases reveals a neutrophilic vasculopathic reaction (Fig. 5), with fibrinoid necrosis of dermal blood vessel walls, perivascular extravasation of fibrin and erythrocytes, and karyorrhectic debris in association with the dermal infiltrate of polymorphonuclear leucocytes $[10,11]$; although the presence of eosinophils may provide a clue to a drug-related cause, one should remain cognizant of the many other potential causes of vasculitis in individuals infected with HIV $[11,12]$ 
Fig. 5. Leucocytoclastic vasculitis, with a neutrophilic vasculopathic reaction and incipient neutrophil-rich subepidermal vesiculation.

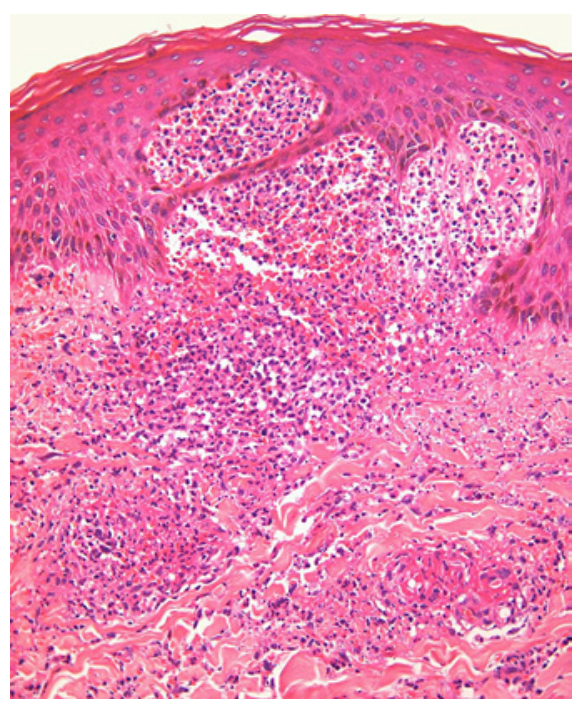

Diagnosis and Management

Diagnosing the type of reaction is imperative as it has an impact on management and treatment interruption. If reactions are minor and self-limiting, symptomatic therapy may be all that is required. If the reaction is persistent or severe, all treatment should be discontinued, the reaction treated and an attempt initiated to identify the drug(s) responsible, with the aim to resume therapy as soon as possible to ensure optimal management of the TB itself.

There is significant morbidity and mortality attributed to suboptimally treated TB, particularly in HIV co-infection. Second-line drugs are less effective and carry their own burden of toxicities $[41,42]$. There is also robust evidence indicating that rifampicin-based regimes are superior to non-rifampicin-based regimes with regard to outcomes and relapse rates, justifying rechallenge in patients who have experienced ACDR to first-line agents both to establish causation and to remove the offending drug [43-46].

There is presently no consensus on the protocol for rechallenge. In previous reports on rechallenge, the sequence was arbitrarily selected. Drugs were commenced after the reaction had subsided, with daily challenge doses starting with those least likely to be implicated, and if no reaction occurred, incremental doses were administered until full doses were tolerated. However, whether rechallenge should occur with full or incremental doses remains unclear. Furthermore, the sequence in which drugs should be reintroduced remains contentious, with some authors suggesting that the least likely offending drug be commenced first, whilst others suggest that the most effective drugs such as rifampicin and isoniazid be reintroduced first to minimise the likelihood of inadequate therapy $[43,47]$. This is further complicated by the lack of unanimity regarding which drug is the most common offending drug.

A retrospective study conducted in a dermatology ward of a tertiary referral hospital in Cape Town, South Africa, reviewed the records on 298 patients with cutaneous drug reactions; $21.8 \%$ of these patients had anti-TB drug-associated ACDR, of whom 92\% were co-infected with HIV [26]. The most common reintroduction reactions were itch (48\%) and hepatitis (39\%). Rifampicin was found to be the offending drug in $57 \%$ of the reintroduction reaction cases, followed by isoniazid (22\%), pyrazinamide (13\%), and ethambutol, streptomycin and ofloxacin (4\% each). The study concluded that all first-line anti-TB drugs could potentially cause ACDR; that HIV co-infection was a significant risk factor; that reintroduction reactions were common, but the majority were mild and non-life-threatening; and that rifampicin was more frequently implicated than formerly described [26]. 

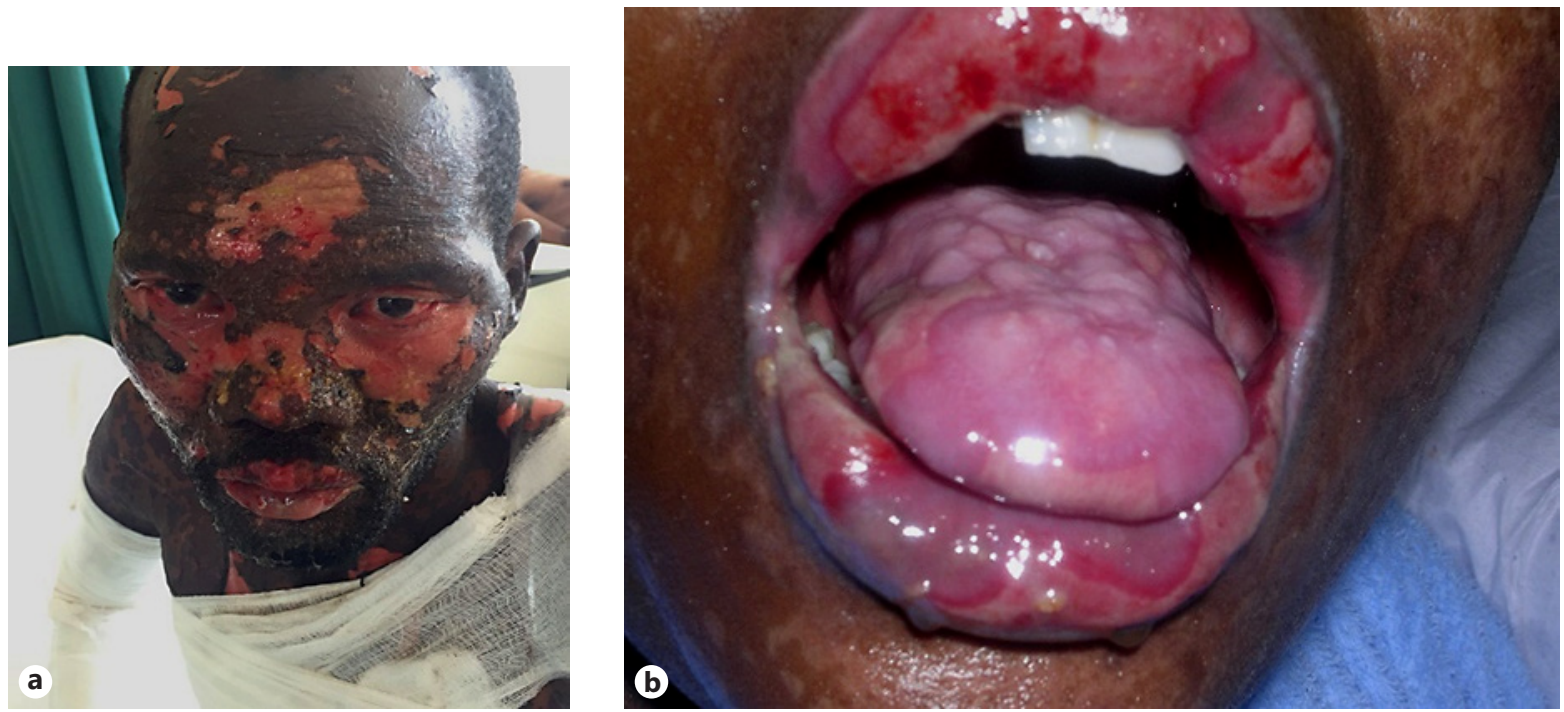

Fig. 6. Stevens-Johnson syndrome. a Conjunctival erosions. b Oral erosions. c Penile erosions.

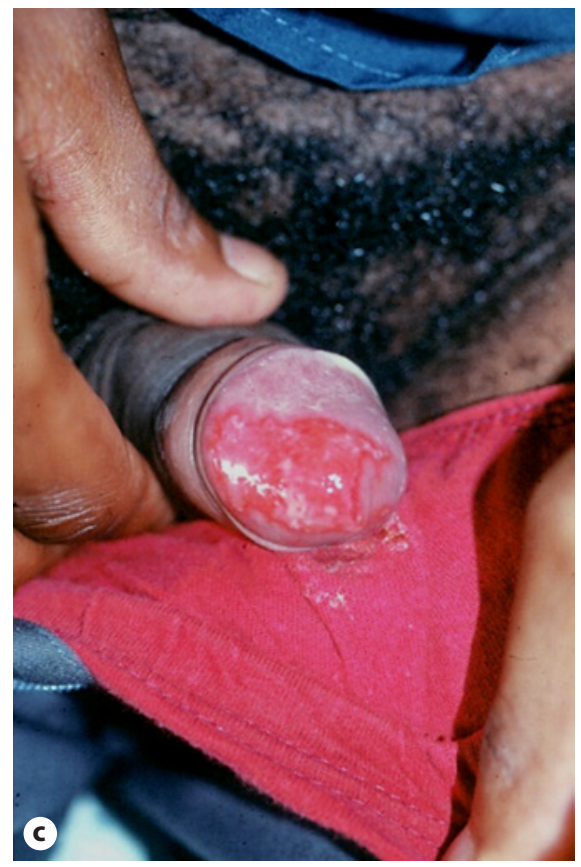

It is the authors' suggestion that rechallenge by first reintroducing those drugs which are least likely to cause a reaction is a realistic option and often efficacious, provided patients are adequately monitored and resources available [26]. However, further prospective studies are required to establish safer reintroduction protocols in resource-limited settings with a high HIV and TB prevalence.

\section{ACDR to Antiretrovirals}

ACDR to almost all antiretrovirals are common, but particularly so to the non-nucleoside reverse transcriptase inhibitors (NNRTIs). NVP and efavirenz (EFV), recommended as firstline agents in resource-limited settings, are both implicated in ACDR [48]. They present most commonly with a morbilliform eruption and urticaria in the first 4-6 weeks after treatment 

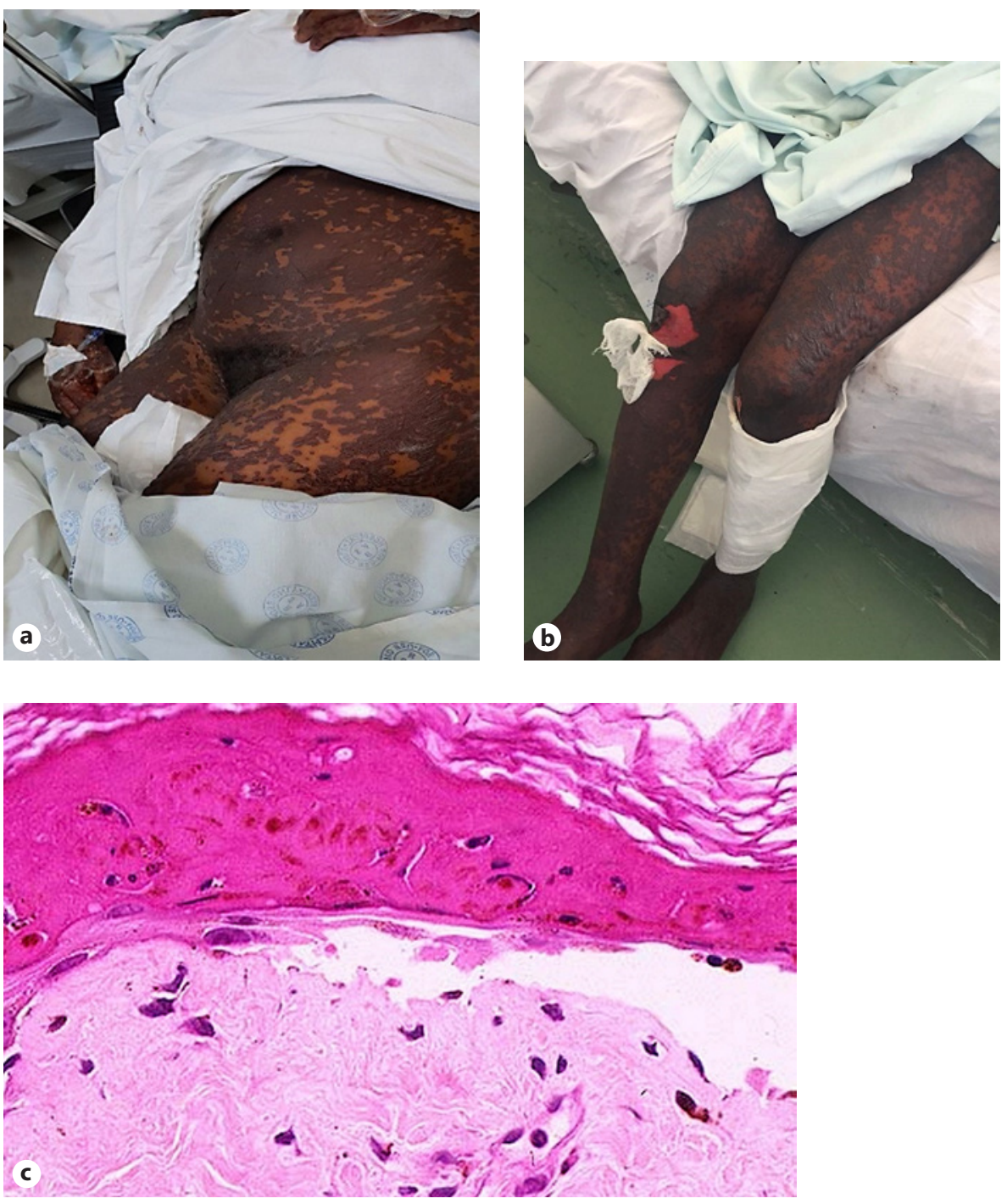

Fig. 7. Toxic epidermal necrolysis. a Generalised erythema multiforme/necrotic lesions. b Imminent stripping of the skin. c Biopsy from the edge of a subepidermal bullous lesion showing full-thickness non-viability of the blister roof.

initiation. The incidence of NVP-associated ACDR has been reported to be $8.9 \%$, with increasing frequency proportional to dose increments [49, 50]. Risk factors for NVP-induced reactions include female sex, plasma drug concentrations $>5.3 \mathrm{mg} / \mathrm{mL}$, being treatment naïve at the time of initiation of therapy and being female with a baseline CD 4 count $>200$ cells $/ \mu \mathrm{L}$ $[50,51]$. In the absence of blisters, erythroderma, mucosal involvement and hepatitis, therapy can be continued uninterrupted and the reaction treated symptomatically with antihistamines and topical corticosteroids.

The incidence of SJS (Fig. 6a-c) and TEN (Fig. 7a, b) is estimated to be around $0.3 \%$ with NVP [52] and usually develops 1-3 weeks after initiation of therapy [8]. This requires prompt recognition and permanent discontinuation of the drug. In these patients, reintroduction is contraindicated. Hence, close monitoring of patients on NVP is essential in the first 6 weeks after treatment initiation and should continue for up to 18 weeks [53]. Patients who develop a rash should always be assessed for hepatotoxicity. SJS exhibits a histological picture indis- 
tinguishable from erythema multiforme, whereas TEN is characterised by subepidermal bulla formation in the presence of full-thickness epidermal necrosis (Fig. 7c) [3, 10,11]. To reduce the incidence of skin rash, NVP should be administered at a dose of $200 \mathrm{mg}$ once a day for the first 2 weeks and $200 \mathrm{mg}$ twice a day thereafter. If a rash develops in the first 2 weeks, then dose escalation should be deferred until the rash resolves [54].

In a case-control analysis conducted in Cape Town, South Africa, which assessed patients with severe skin reactions on combination antiretroviral therapy, it was reported that the most severe reactions resulting in admission were SJS/TEN and DHS. Most cases occurred in the first 2 months after initiation of therapy, and both NVP exposure and pregnancy were associated with severe skin reactions. There was a significant mortality of $4 \%$ with severe reactions [48]. The high risk of severe reactions with NVP is similar to that reported in previous studies.

Adverse Cutaneous Reactions Associated with the Newest Antiretroviral Drugs

- Tipranavir: a protease inhibitor (PI) approved for use with ritonavir for patients with PI resistance; the most common ACDR are urticaria, morbilliform rash or photosensitive lesions with onset usually around day 53, occurring in up to $8-14 \%$ of patients [55]; it contains a sulphonamide moiety, and sulpha-containing drugs should be used with caution, although sulphonamide allergy is not an absolute contraindication [8,56,57]

- Darunavir: in clinical trials of this PI, rashes occurred in 7\% of cases, which were mostly self-limited and morbilliform; 1 case of SJS was reported $[8,58]$

- Etravirine: a new NNRTI which has been used in patients with NNRTI resistance; ACDR were reported in $16.9 \%$ of cases, the majority of which were mild-to-moderate morbilliform lesions arising in the first few weeks and resolving with continued treatment; the reactions were more common in females than in males; severe reactions including erythema multiforme, SJS and DHS were reported in $<0.1 \%$ of patients $[8,59,60]$

- Raltegravir: an integrase inhibitor; patients in trials were reported to present with mildto-moderate rash and pruritus, with 2 cases of hypersensitivity $[8,61]$

- Maraviroc: a CCR5 chemokine receptor inhibitor; a pruritic rash occurred in 3.8\% of patients, which may precede hepatotoxicity; therefore, patients with rash, eosinophilia and raised IgE should be evaluated for hepatotoxicity $[8,62]$

Hypersensitivity Syndrome

This is a life-threatening reaction which occurs in the first 42 days of antiretroviral therapy. It presents with a diffuse maculopapular eruption, fever, eosinophilia, atypical lymphocytosis, multivisceral involvement and raised liver enzyme levels ( $>5$-times elevated transaminases). It occurs most commonly with NVP (2\%), EFV, abacavir, amprenavir and indinavir. The mortality rate is $10 \%$ with NVP, usually due to liver failure. It is reported in up to $2.3-9 \%$ of patients on abacavir usually within the first 6 weeks of exposure and resolves within $72 \mathrm{~h}$ of drug withdrawal. If hypersensitivity is suspected, the drug must be discontinued. Rechallenge following hypersensitivity is contraindicated [63-65].

Recurring Drug Reactions

These reactions can seriously impede effective management of HIV and opportunistic infections in patients presenting with persistent non-life-threatening drug reactions or recurrent reactions. They present during the first 8 weeks of therapy, coinciding with a rise in CD4 cell counts, and occur as a manifestation of immune reconstitution. The use of a protracted course of steroids $(0.5 \mathrm{mg} / \mathrm{kg}$ for the first 8 weeks of therapy) in patients who develop recurrent and potentially severe cutaneous eruptions and have a previous history of ACDR allows suppression of reactions whilst initiating and continuing essential drugs [66]. 
Hoosen et al.: Cutaneous Drug Reactions in HIV

\section{Conclusions}

The global mortality from HIV has significantly declined due to highly active antiretroviral therapy. Mutually, cutaneous manifestations of HIV have been considerably reduced by $40 \%$ and dermatological consultations by $63 \%$, and the resultant burden of disease from AIDS-associated inflammatory, infective and malignant disorders has been substantially diminished, enabling patients to enjoy a superior quality of life [67]. Reciprocally, there has been a concurrent increase in the incidence of cutaneous drug reactions in HIV-infected individuals, the most severe being SJS, TEN and hypersensitivity syndrome [67]. With regard to antiretrovirals, these severe life-threatening adverse cutaneous reactions occur most commonly with the NNRTIs NVP and EFV, the NRTI abacavir, and the PIs indinavir and amprenavir. Most reactions (86\%) occur within 4 weeks of therapy. The frequent encumbrance of opportunistic infections in HIV often leads to the concurrent use of TMP/SMX for PJP prophylaxis and anti-TB therapy, both of which are well-documented instigators of both mild and severe ACDR.

Prompt diagnosis of the ACDR, isolation of the offending agent and treatment of the reaction are warranted, since severe reactions mandate immediate treatment discontinuation without rechallenge to avert further progression. Appropriate drug substitution for the underlying disorder should be instituted accordingly.

Further prospective studies are required to bridge the disparities in the current knowledge of ACDR in the setting of HIV, including causative drugs, incidence rates, risk factors, management and appropriate rechallenge protocols. The future holds the attractive prospect of predictive genetic testing and simple screening tests for drug-specific ACDR [19].

\section{Statement of Ethics}

The authors have no ethical conflicts to disclose.

\section{Disclosure Statement}

The authors have no conflicts of interest to declare. There was no funding source for this work.

\section{Author Contributions}

All authors contributed equally to the paper, are equally accountable for the accuracy and integrity of the content, and will ensure that questions related to the integrity of any part of the work are appropriately investigated and resolved. Major acquisition, review and interpretation of literature was undertaken by K.H., who also contributed substantially to the conception and design of the work, drafting of the content and revision of the intellectual content of the draft. A.M. contributed to literature acquisition, literature review and critical revision of the draft. K.H. and A.M. provided the clinical images related to the discussion. N.C.D. and W.G. assisted with the conception of the content and the literature review. W.G. was responsible for photomicrography and discussion of the histopathological results. K.H., A.M. and W.G. were responsible for final approval of the submitted version. 
Hoosen et al.: Cutaneous Drug Reactions in HIV

\section{References}

1 Carr A, Cooper DA. Adverse effects of antiretroviral therapy. Lancet. 2000 Oct;356(9239):1423-30.

2 Battegay M, Opravil M, Wüthrich B, Lüthy R. Rash with amoxycillin-clavulanate therapy in HIV-infected patients. Lancet. 1989 Nov;2(8671):1100.

3 Coopman SA, Stern RS. Cutaneous drug reactions in human immunodeficiency virus infection. Arch Dermatol. 1991 May;127(5):714-7.

4 Jick H. Adverse reactions to trimethoprim-sulfamethoxazole in hospitalized patients. Rev Infect Dis. 1982 Mar-Apr;4(2):426-8.

5 De Raeve L, Song M, Van Maldergem L. Adverse cutaneous drug reactions in AIDS. Br J Dermatol. 1988 Oct; 119(4):521-3.

6 Mitsuyasu R, Groopman J, Volberding P. Cutaneous reaction to trimethoprim-sulfamethoxazole in patients with AIDS and Kaposi's sarcoma. N Engl J Med. 1983 Jun;308(25):1535-6.

7 van der Ven AJ, Koopmans PP, Vree TB, van der Meer JW. Adverse reactions to co-trimoxazole in HIV infection. Lancet. 1991 Aug;338(8764):431-3.

8 Borrás-Blasco J, Navarro-Ruiz A, Borrás C, Casterá E. Adverse cutaneous reactions associated with the newest antiretroviral drugs in patients with human immunodeficiency virus infection. J Antimicrob Chemother. 2008 Nov;62(5):879-88.

9 Johnson RA. Cutaneous manifestations of human immunodeficiency virus disease. In: Friedberg IM, Eisen AZ, Wolf K, Austen KF, Goldsmith LA, Katz SI, et al., editors. Fitzpatrick's textbook of dermatology. 5th ed. New York (NY): McGraw-Hill; 1999. Ch. 225, p. 2138-50.

10 Horn TD, Hiatt KM. Cutaneous toxicities of drugs. In: Elder DE, Elenitsas R, Johnson Jr BL, Murphy GF, editors. Levers histopathology of the skin. 9th ed. Philadelphia (PA): Lippincott Williams \& Wilkins; 2005. Ch. 11, p. 324-40.

11 Grayson W. The HIV-positive skin biopsy. J Clin Pathol. 2008 Jul;61(7):802-17.

12 Walker S, Grayson W. Human immunodeficiency virus (HIV) and acquired immunodeficiency syndrome (AIDS)-associated cutaneous diseases. In: Calonje EJ, Brenn T, Lazar A, Billings S, editors. McKee’s pathology of the skin with clinical correlations. 5th ed. Philadelphia (PA): Elsevier; 2019. vol. 2, Ch. 19, p. 976-89.

13 Chang HM, Tsai HC, Lee SS, Kunin C, Lin PC, Wann SR, et al. High daily doses of trimethoprim/sulfamethoxazole are an independent risk factor for adverse reactions in patients with pneumocystis pneumonia and AIDS. J Chin Med Assoc. 2016 Jun;79(6):314-9.

14 Wang D, Curtis A, Papp AC, Koletar SL, Para MF. Polymorphism in glutamate cysteine ligase catalytic subunit (GCLC) is associated with sulfamethoxazole-induced hypersensitivity in HIV/AIDS patients. BMC Med Genomics. 2012 Jul;5(1):32.

15 Patel RM, Marfatia YS. Clinical study of cutaneous drug eruptions in 200 patients. Indian J Dermatol Venereol Leprol. 2008 Jul-Aug; 74(4):430.

16 Carr A, Penny R, Cooper DA. Efficacy and safety of rechallenge with low-dose trimethoprim-sulfamethoxazole in previously hypersensitive HIV-infected patients. AIDS. 1993 Jan;7(1):65-71.

17 Belchi-Hernandez J, Espinosa-Parra FJ. Management of adverse reactions to prophylactic trimethoprimsulphamethoxazole in patients with human immunodeficiency virus infection. Ann Allergy Asthma Immunol. 1996 Apr;76(4):355-8.

18 Kuaban C, Bercion R, Koulla-Shiro S. HIV seroprevalence rate and incidence of adverse skin reactions in adults with pulmonary tuberculosis receiving thiacetazone free anti-tuberculosis treatment in Yaounde, Cameroon. East Afr Med J. 1997 Aug;74(8):474-7.

19 Lehloenya RJ, Dheda K. Cutaneous adverse drug reactions to anti-tuberculosis drugs: state of the art and into the future. Expert Rev Anti Infect Ther. 2012 Apr;10(4):475-86.

20 Toma E, Fournier S. Adverse reactions to co-trimoxazole in HIV infection. Lancet. 1991 Oct;338(8772):954.

21 From the Centers for Disease Control and Prevention. Serious adverse events attributed to nevirapine regimens for postexposure prophylaxis after HIV exposures - worldwide, 1997-2000. JAMA. 2001 Jan;285(4): 402-3.

22 Marks DJ, Dheda K, Dawson R, Ainslie G, Miller RF. Adverse events to antituberculosis therapy: influence of HIV and antiretroviral drugs. Int J STD AIDS. 2009 May;20(5):339-45.

23 Yee D, Valiquette C, Pelletier M, Parisien I, Rocher I, Menzies D. Incidence of serious side effects from first-line antituberculosis drugs among patients treated for active tuberculosis. Am J Respir Crit Care Med. 2003 Jun; 167(11):1472-7.

24 Pozniak AL, MacLeod GA, Mahari M, Legg W, Weinberg J. The influence of HIV status on single and multiple drug reactions to antituberculous therapy in Africa. AIDS. 1992 Aug;6(8):809-14.

25 Tan WC, Ong CK, Kang SC, Razak MA. Two years review of cutaneous adverse drug reaction from first line antituberculous drugs. Med J Malaysia. 2007 Jun;62(2):143-6.

26 Lehloenya RJ, Todd G, Badri M, Dheda K. Outcomes of reintroducing anti-tuberculosis drugs following cutaneous adverse drug reactions. Int J Tuberc Lung Dis. 2011 Dec;15(12):1649-57.

27 Bigby M. Rates of cutaneous reactions to drugs. Arch Dermatol. 2001 Jun;137(6):765-70.

28 Nunn P, Kibuga D, Gathua S, Brindle R, Imalingat A, Wasunna K, et al. Cutaneous hypersensitivity reactions due to thiacetazone in HIV-1 seropositive patients treated for tuberculosis. Lancet. 1991 Mar;337(8742):627-30. 
29 Walsh SA, Creamer D. Drug reaction with eosinophilia and systemic symptoms (DRESS): a clinical update and review of current thinking. Clin Exp Dermatol. 2011 Jan;36(1):6-11.

30 Rebollo S, Sanchez P, Vega JM, Sedano E, Sanchís ME, Asensio T, et al. Hypersensitivity syndrome from isoniazid with positive patch test. Contact Dermat. 2001 Nov;45(5):306.

31 Pitche P, Mouzou T, Padonou C, Tchangai-Walla K. [Stevens-Johnson syndrome and toxic epidermal necrolysis after intake of rifampicin-isoniazid: report of 8 cases in HIV-infected patients in Togo]. Med Trop (Mars). 2005 Sep;65(4):359-62.

32 Sarkar SK, Purohit SD, Sharma TN, Chawla MP, Gupta DN. Stevens-Johnson syndrome caused by streptomycin. Tubercle. 1982 Jun;63(2):137-8.

33 Digwood-Lettieri S, Reilly KJ, Haith LR Jr, Patton ML, Guilday RJ, Cawley MJ, et al. Levofloxacin-induced toxic epidermal necrolysis in an elderly patient. Pharmacotherapy. 2002 Jun;22(6):789-93.

34 Pegram PS Jr, Mountz JD, O’Bar PR. Ethambutol-induced toxic epidermal necrolysis. Arch Intern Med. 1981 Nov;141(12):1677-8.

35 Surjapranata FJ, Rahaju NN. A case of Stevens-Johnson's syndrome caused by ethambutol. Paediatr Indones. 1979 Jul-Aug; 19(7-8):195-201.

36 Grossman ME, Warren K, Mady A, Satra KH. Lichenoid eruption associated with ethambutol. J Am Acad Dermatol. 1995 Oct;33(4):675-6.

37 Lee AY, Jung SY. Two patients with isoniazid-induced photosensitive lichenoid eruptions confirmed by photopatch test. Photodermatol Photoimmunol Photomed. 1998 Apr;14(2):77-8.

38 Kim JH, Moon JI, Kim JE, Choi GS, Park HS, Ye YM, et al. Cutaneous leukocytoclastic vasculitis due to anti-tuberculosis medications, rifampin and pyrazinamide. Allergy Asthma Immunol Res. 2010 Jan;2(1):55-8.

39 Iredale JP, Sankaran R, Wathen CG. Cutaneous vasculitis associated with rifampin therapy. Chest. 1989 Jul; 96(1):215-6.

40 Chan CH, Chong YW, Sun AJ, Hoheisel GB. Cutaneous vasculitis associated with tuberculosis and its treatment. Tubercle. 1990 Dec;71(4):297-300.

41 Schaberg T, Rebhan K, Lode H. Risk factors for side-effects of isoniazid, rifampin and pyrazinamide in patients hospitalized for pulmonary tuberculosis. Eur Respir J. 1996 0ct;9(10):2026-30.

42 Orenstein EW, Basu S, Shah NS, Andrews JR, Friedland GH, Moll AP, et al. Treatment outcomes among patients with multidrug-resistant tuberculosis: systematic review and meta-analysis. Lancet Infect Dis. 2009 Mar; 9(3): 153-61.

43 Joint Tuberculosis Committee of the British Thoracic Society. Chemotherapy and management of tuberculosis in the United Kingdom: recommendations 1998. Thorax. 1998 Jul;53(7):536-48.

44 Controlled clinical trial of four short-course (6-month) regimens of chemotherapy for treatment of pulmonary tuberculosis. Third report. East African-British Medical Research Councils. Lancet. 1974 Aug;2(7875):23740 .

45 Controlled clinical trial of four short-course regimens of chemotherapy for two durations in the treatment of pulmonary tuberculosis. Second report. Third East African/British Medical Research Council Study. Tubercle. 1980 Jun;61(2):59-69.

46 Corbett EL, Watt CJ, Walker N, Maher D, Williams BG, Raviglione MC, et al. The growing burden of tuberculosis: global trends and interactions with the HIV epidemic. Arch Intern Med. 2003 May;163(9):1009-21.

47 Suzuki Y, Miwa S, Shirai M, Ohba H, Murakami M, Fujita K, et al. Drug lymphocyte stimulation test in the diagnosis of adverse reactions to antituberculosis drugs. Chest. 2008 Nov;134(5):1027-32.

48 Stewart A, Lehloenya R, Boulle A, de Waal R, Maartens G, Cohen K. Severe antiretroviral-associated skin reactions in South African patients: a case series and case-control analysis. Pharmacoepidemiol Drug Saf. 2016 Nov;25(11):1313-9.

49 de Maat MM, ter Heine R, Mulder JW, Meenhorst PL, Mairuhu AT, van Gorp EC, et al. Incidence and risk factors for nevirapine-associated rash. Eur J Clin Pharmacol. 2003 Sep;59(5-6):457-62.

50 Bersoff-Matcha SJ, Miller WC, Aberg JA, van der Horst C, Hamrick HJ Jr, Powderly WG, et al. Sex differences in nevirapine rash. Clin Infect Dis. 2001 Jan;32(1):124-9.

51 van Leth F, Andrews S, Grinsztejn B, Wilkins E, Lazanas MK, Lange JM, et al.; 2NN Study Group. The effect of baseline CD4 cell count and HIV-1 viral load on the efficacy and safety of nevirapine or efavirenz-based firstline HAART. AIDS. 2005 Mar;19(5):463-71.

52 Hawkins T. Appearance-related side effects of HIV-1 treatment. AIDS Patient Care STDS. 2006 Jan;20(1):6-18.

53 Boehringer Ingelheim Pharmaceuticals, Inc. Viramune ${ }^{\circledR}$ prescribing information [package insert]. Ridgefield (CT): Boehringer Ingelheim Pharmaceuticals, Inc.; 2007.

54 Drugs for HIV infection: treatment guidelines. The Medical Letter. 2006 Oct;4(50):67-76.

55 Boehringer Ingelheim Pharmaceuticals, Inc. Product information. Aptivus (Tipranavir). Ridgefield (CT): Boehringer Ingelheim Pharmaceuticals, Inc.; 2007.

56 Gathe J, Cooper DA, Farthing C, Jayaweera D, Norris D, Pierone G Jr, et al.; RESIST-1 Study Group. Efficacy of the protease inhibitors tipranavir plus ritonavir in treatment-experienced patients: 24-week analysis from the RESIST-1 trial. Clin Infect Dis. 2006 Nov;43(10):1337-46.

57 Cahn P, Villacian J, Lazzarin A, Katlama C, Grinsztejn B, Arasteh K, et al. Ritonavir-boosted tipranavir demonstrates superior efficacy to ritonavir-boosted protease inhibitors in treatment-experienced HIV-infected patients: 24-week results of the RESIST-2 trial. Clin Infect Dis. 2006 Nov;43(10):1347-56. 
58 Madruga JV, Berger D, McMurchie M, Suter F, Banhegyi D, Ruxrungtham K, et al.; TITAN Study Group. Efficacy and safety of darunavir-ritonavir compared with that of lopinavir-ritonavir at 48 weeks in treatment-experienced, HIV-infected patients in TITAN: a randomised controlled phase III trial. Lancet. 2007 Jul;370(9581): 49-58.

59 Madruga JV, Cahn P, Grinsztejn B, Haubrich R, Lalezari J, Mills A, et al.; DUET-1 Study Group. Efficacy and safety of TMC125 (etravirine) in treatment-experienced HIV-1-infected patients in DUET-1: 24-week results from a randomised, double-blind, placebo-controlled trial. Lancet. 2007 Jul;370(9581):29-38.

60 Lazzarin A, Campbell T, Clotet B, Johnson M, Katlama C, Moll A, et al.; DUET-2 Study Group. Efficacy and safety of TMC125 (etravirine) in treatment-experienced HIV-1-infected patients in DUET-2: 24-week results from a randomised, double-blind, placebo-controlled trial. Lancet. 2007 Jul;370(9581):39-48.

61 Markowitz M, Morales-Ramirez JO, Nguyen BY, Kovacs CM, Steigbigel RT, Cooper DA, et al. Antiretroviral activity, pharmacokinetics, and tolerability of MK-0518, a novel inhibitor of HIV-1 integrase, dosed as monotherapy for 10 days in treatment-naive HIV-1-infected individuals. J Acquir Immune Defic Syndr. 2006 Dec; 43(5):509-15.

62 Nelson M, Fätkenheuer G, Konourina I, Lazzarin A, Clumeck N, Horban A, et al. Efficacy and safety of maraviroc plus optimized background therapy in viremic, ART-experienced patients infected with CCR5-tropic HIV-1 in Europe, Australia and North America: 24-week results. In: Abstracts of the Fourteenth Conference on Retroviruses and Opportunistic Infections, Los Angeles, CA. 2007. Abstract 104aLB, plus oral presentation.

63 Clay PG. The abacavir hypersensitivity reaction: a review. Clin Ther. 2002 Oct;24(10):1502-14.

64 Dando TM, Scott LJ. Abacavir plus lamivudine: a review of their combined use in the management of HIV infection. Drugs. 2005;65(2):285-302.

65 Lucas A, Nolan D, Mallal S. HLA-B*5701 screening for susceptibility to abacavir hypersensitivity. J Antimicrob Chemother. 2007 Apr;59(4):591-3.

66 Dolev J, Reyter I, Maurer T. Treatment of recurring cutaneous drug reactions in patients with human immunodeficiency virus 1 infection: a series of 3 cases. Arch Dermatol. 2004 Sep;140(9):1051-3.

67 Calista D, Morri M, Stagno A, Boschini A. Changing morbidity of cutaneous diseases in patients with HIV after the introduction of highly active antiretroviral therapy including a protease inhibitor. Am J Clin Dermatol. 2002;3(1):59-62. 